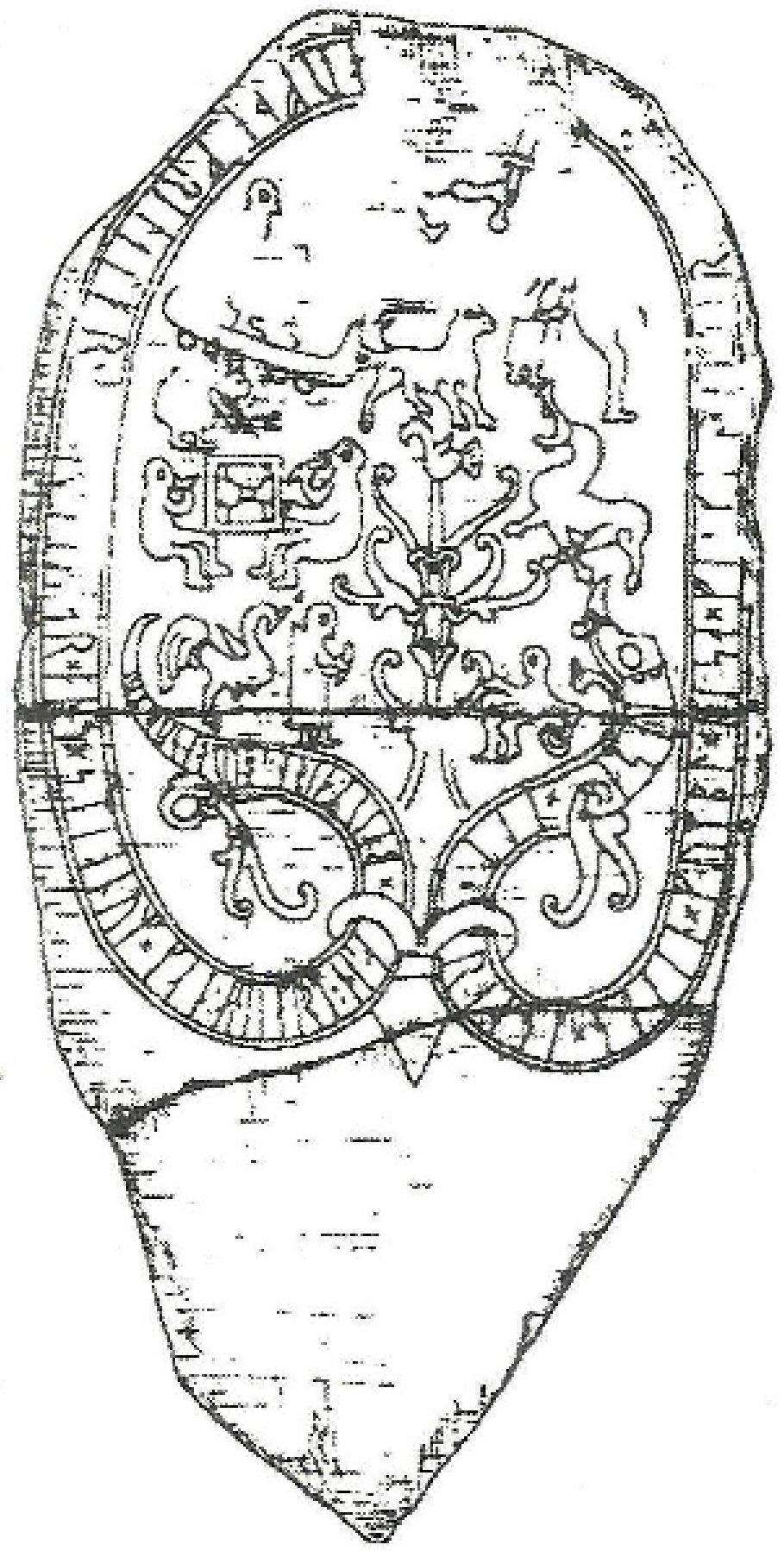

Pedra rúnica de Ockelbo (Gs 19).

Fonte: Marez (2007, p. 416). 


\title{
O Céu dos Vikings: Uma Interpretação Etnoastronômica da Pedra Rúnica de Ockelbo (GS 19)
}

\author{
Johnni Langer \\ Doutorado em História (UFPR, 2001) e Pós-Doutorado em História Medieval pela USP (2006-2007). Atua \\ principalmente nos temas de história e cultura na Era Viking e na Escandinávia Medieval. É coordenador \\ do NEVE (Núcleo de Estudos Vikings e Escandinavos) e Professor Adjunto da Universidade Federal do \\ Maranhão (UFMA).
}

\begin{abstract}
ResUMO
O presente trabalho faz uma análise comparativa entre história e cinema, utilizando as discussões $O$ presente artigo propõe algumas interpretações iconográficas para a pedra rúnica de Ockelbo (Gs 19), monumento erigido na Escandinávia durante a Era Viking (793-1066 d.C.). A investigação propõe uma análise através do referencial da Etnoastronomia, em convergência com os estudos de mitologia comparada e da História cultural. Nossa principal hipótese é a de que este monumento possui referências cosmológicas e astronômicas, centralizadas na representação mitológica da Via Láctea e constelações correlacionadas a esta.

Palavras-chave: Escandinávia da Era Viking. Etnoastronomia medieval. Mitologia nórdica.
\end{abstract}

\section{Abstract}

This article proposes some iconographic interpretations for the runestone of Ockelbo (Gs 19), monument erected in Scandinavia during the Viking Age (AD 793-1066). The research proposes an analysis by the Ethnoastronomy, in convergence with studies of comparative mythology and cultural history. Our main hypothesis is that this monument has cosmological and astronomical references, centered on the mythological representation of the Milky Way and constellations correlated to this.

Keywords: Viking Age Scandinavia. Medieval Ethnoastronomy. Norse Mythology. 


\section{Introdução}

A Escandinávia da Era Viking (793-1066 d. C.) foi um momento extremamente rico em produções imagéticas. Tanto objetos cotidianos, como joias, adornos, utensílios e ferramentas, como em gravuras de monumentos e inscrições são repletos de referenciais visuais. Seja na forma de símbolos puramente ornamentais como em complexas cenas advindas da mitologia, da história e da sociedade nórdica, estas imagens ainda são pouco estudadas, sendo tradicionalmente preteridas às fontes escritas e documentais. A relação entre texto e imagem neste contexto histórico também é incipiente, mas uma nova disciplina acadêmica vem oferecendo algumas interessantes opções metodológicas, a Etnoastronomia. Apesar disso, sua aplicação tem sido mais comum entre os países do Leste europeu, sendo a área nórdica medieval ainda sujeita a inúmeras possibilidades de investigação. O objetivo principal deste artigo é fornecer algumas hipóteses interpretativas a um material ainda muito pouco estudado: os vestígios visuais da mitologia escandinava.

Entendemos Etnoastronomia dentro de uma perspectiva que procura reconstituir o conhecimento astronômico dos povos antigos e sua relação na religiosidade, na sociedade e na arte. A associação entre iconografia, texto e ritual é uma das determinantes neste estudo, procurando encontrar o ponto de convergência entre a tradição de observação do céu e o registro monumental e/ou visual (BAITY, 1973, p. 403). Apesar de não adotarmos um referencial de determinismo da natureza sobre a cultura, acreditamos que os fenômenos cósmicos e astronômicos foram muito importantes na criação e desenvolvimento de diversas narrativas mitológicas, e é basicamente pelas imagens que estas cenas foram preservadas pela tradição folclórica, lado a lado com a oralidade (VERDET, 1987, p. 19).

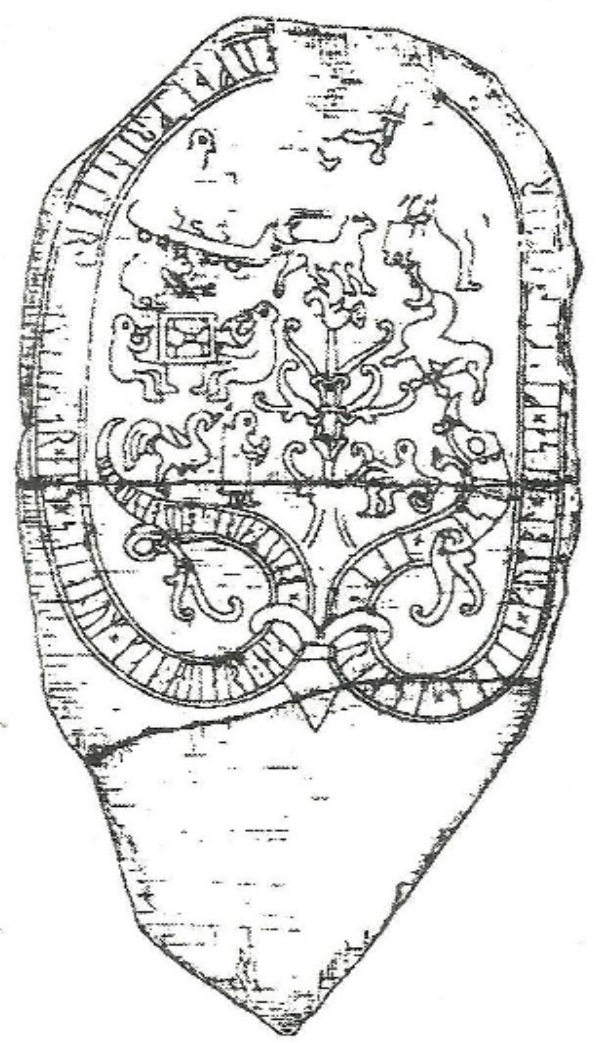

Figura 1- Pedra rúnica de Ockelbo (Gs 19). Fonte: Marez (2007, p. 416).

\section{Iconografia}

Nossa principal fonte de estudo é o monumento sueco conhecido como pedra rúnica (runestone) Gs 19 (figura 1), erigido durante o século XI d. C. e preservado na igreja de Ockelbo, Gästrikland, Suécia, sendo descoberto em 1795 e destruído durante um incêndio em 1904. Atualmente ele foi reconstituído a partir de ilustrações oitocentistas e fotografias do início do século XX. Devido ao fato de ter sido destruído, não tivemos acesso aos detalhes materiais do monumento original (como peso, altura, composição, etc.). As runestones foram 
erigidas como memoriais de mortos, registro de patrocínios e comemorações da memória individual, apresentando imagens que na maioria das vezes não tem relação direta com o conteúdo das inscrições rúnicas (como é o caso de Gs 19) (SAWYER, 2003, p. 2; 20). Runas são as letras do alfabeto dos povos germânicos, utilizadas até o advento do período moderno.

O padrão artístico de Gs 19 é denominado de Ringerike ( $\operatorname{Pr} 2)$, uma estética desenvolvida entre o final do século X a início do XI d. C. Sua principal característica é a retratação de temas animais, como pássaros e leões, mesclados a linha sinuosas e espiraladas. O estilo da pedra rúnica de Eckelbo é o formato olândico, cuja rocha possui formato semicônico e afunilando-se na ponta. $\mathrm{O}$ motivo principal é o de uma serpente, em cujo interior foram realizadas cenas, símbolos e ornamentos, e em cujo corpo foram esculpidas runas. A serpente entrelaça-se com sua cauda formando um semicírculo oblongo, sendo fechada com uma espécie de argola dupla, e tendo tanto a cabeça quanto o rabo projetadas com ornamentos espiralados. A figura central do monumento é a representação de uma árvore, constituída por nove ramos também terminados com a ponta em semiespiral. No topo do tronco foi gravado um pássaro (figura 1).

A cena superior é a que apresenta maiores desgastes, mas pode-se perceber uma perna e um braço segurando uma espada e sendo esta introduzida no dorso superior da serpente. Logo abaixo foi representada uma carroça e um cavalo, sendo conduzida por um homem (do qual só são visíveis a cabeça e as pernas). À frente da carroça temos duas pessoas onde só é perceptível a perna de ambos, mas o primeiro parece estar portando uma lança. Abaixo da carroça, um homem inclina-se e denota estar segurando flechas ou um objeto não identificado. Ainda abaixo, surge a representação de dois homens sentados, divertindo-se com um jogo de tabuleiro e um deles porta um corno, sendo o mesmo levado à sua boca. Ao lado direito da árvore, surge um cavalo, preso a um dos ramos por meio de um anel/argola. Lobo abaixo, a figura de um homem, segurando um dos ramos com a mão direita e portando um anel com a outra. Do lado oposto da árvore, na mesma altura, percebemos uma mulher portando um corno e logo atrás dela, surge a figura de um galo (figura 1).

\section{Interpretação}

Basicamente, o monumento em questão apresenta um tradicional motivo de serpente entrelaçando várias cenas mitológicas - um padrão genérico da maioria das runestones suecas - e imagens do cotidiano durante a Era Viking - estas, por sua vez, totalmente escassas da iconografia nórdica. A estela foi tradicionalmente interpretada como contendo várias alusões ao ciclo nibelungiano ou do herói Sigurd, incluindo a morte do dragão Fáfnir, um episódio extremamente importante para o paganismo nórdico e que foi preservado em vários outros monumentos da Europa Setentrional ao final da Alta Idade Média, inclusive em igrejas cristãs. Os escassos estudos que citam Eckelbo apresentam duas perspectivas básicas, geralmente separadas umas as outras: a de cenas do cotidiano, como a da mesa de jogo - considerada uma situação de inverno na Escandinávia - caça e transporte com carroça; e outra, a de imagens mitológicas do herói Sigurd, presentes nas fontes literárias e em muitas outras iconografias europeias (STERN, 2009; p. 899-900; DÜWELL, 1988, p. 133156). Até o presente momento não houve 
uma associação das cenas deste monumento com interpretações astronômicas ou de uma comparação sistemática com outras imagens de cunho cosmológico no mundo escandinavo.

O cavalo geralmente é identificado a Grani (o corcel de Sigurd) e também surge amarrado a uma árvore nas inscrições rúnicas de Sö 327 e Sö 101 (figura 5). O homem portando anel é associado com o anão Andvari ou o próprio Sigurd portando o anel Andvaranaut. O elemento mais objetivo de identificação com os mitos nibelungianos é o detalhe parcialmente destruído em Eckelbo, bem acima da figuração da árvore, onde se percebe um braço portando uma espada. Esta cena corresponde à morte do dragão Fáfnir por Sigurd, e surge claramente nas figurações de U 116, U 1175, Gs 2, Sö 327 e Sö 101. Em Eckelbo, o corpo deste dragão contorna todo o conjunto imagético da estela, formando um círculo imperfeito e em cujo interior do dorso foram inscritas runas. As menções ao ciclo são completadas com a figura de uma mulher portando um corno com as mãos, uma alusão a uma valquíria, talvez Sigdrífa - situada no lado oposto ao homem com anel na árvore. Esta mesma cena aparece no monumento U 116. A árvore de Ockelbo e o pássaro em seu topo foram interpretados como sendo o momento em que Sigurd, logo após matar o dragão Fáfnir, obtém o dom de reconhecer a fala dos pássaros de um bosque (DÜWEL, 1988, p. 135).

Com isso, de maneira genérica, os estudos acadêmicos interpretam essa fonte imagética como o registro do ciclo nibelungiano e a inclusão das cenas cotidianas não teria relação direta com as mesmas. De nossa parte, partimos de uma hipótese geral de que este monumento, independente das intenções do artista ou do patrocinador, podia ser percebido em termos cosmológicos mais gerais: o cotidiano estava inserido em um drama cósmico. Ao mesmo tempo em que algumas cenas podem ser percebidas em um contexto individual e ter relação com um contexto cosmológico e vínculos analógicos, como veremos em detalhes mais adiante.

Não negamos a interpretação de algumas cenas de Ockelbo como sendo nibelungianas. Mas em outros monumentos, os dados dessa narrativa mitológica são muito mais individualizados e restritos ao seu contexto imagético, como as cruzes britânicas de Maughold e Halton, onde os dois pássaros e os cavalos são única e exclusivamente alusões ao ciclo nibelungiano. Em Ockelbo a soma de várias cenas como o pássaro acima da árvore, o cavalo preso, o homem portando o anel e a morte do dragão correspondem, sem dúvidas, a uma leitura visual possível: uma transmissão imagética de um importante narrativa oral do paganismo nórdico - a história de Sigurd. Mas ao mesmo tempo, a centralização da árvore no conjunto, com somente um único pássaro em seu topo, também pode ser interpretada visualmente como a árvore do mundo, a Yggdrasill, aos olhos do escandinavo medieval.

Nas fontes mitológicas nórdicas, temos a figura de uma árvore que seria o centro do mundo e ligando todo o cosmos, antevista pelos germanos antigos como Irminsul (coluna gigantesca). Além de fonte da vida, do saber e do destino, ela era transfigurada em cultos religiosos de árvores (BOYER, 1981, p. 212-222). A mítica árvore era habitada por diversos animais, entre os quais uma águia (identificada a Odin) que ficava situada em seu cimo (Grímnismál 31). Existem poucas imagens da Era Viking que podem aludir diretamente a esse mito. Uma delas é a tapeçaria de Överhogdal, originada da Suécia entre os anos 800 a 1000 (figura 2). Cercada em meio a dezenas 
de animais, principalmente cavalos, renas e alces, situam-se duas representações de
Figura 2- Detalhe da tapeçaria de Överhogdal, Suécia, Era Viking.

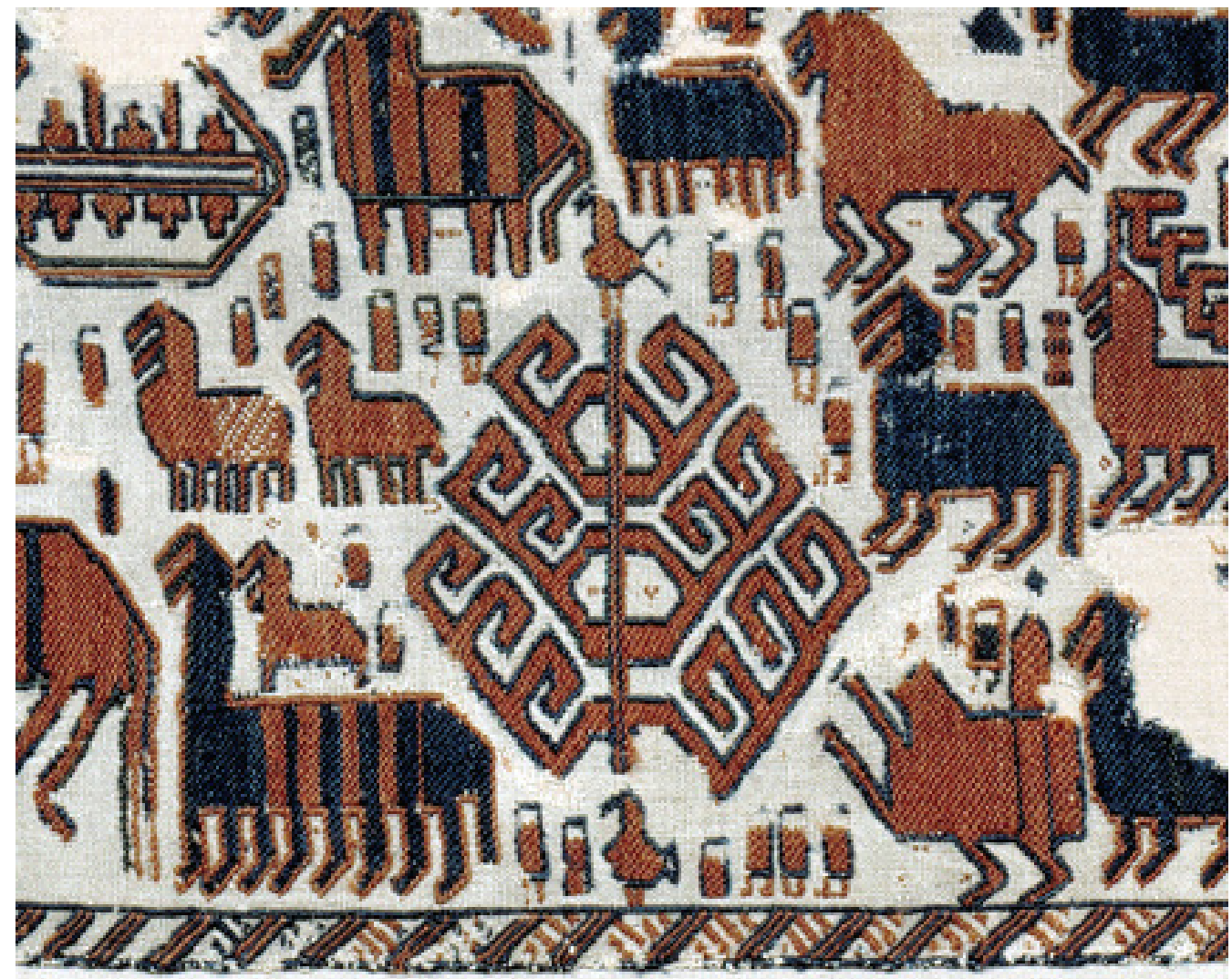

árvores na tapeçaria - separadas em níveis diferentes. Ambas foram tecidas com aspecto geométrico e possuindo um pássaro no topo. Um dos cavalos desta tapeçaria possui oito patas, uma alusão direta a Sleipnir, o corcel de Odin. Algumas pingentes e braceletes da Escandinávia antiga e alto medieval também trazem figuras de árvores, com formas muito semelhantes a de Eckelbo e Överhogdal, sem alusão a qualquer animal mas portando três raízes, o que às vincula ao contexto mitológico da árvore cósmica. Em outras estelas rúnicas, como U 1163, G 2 e Gs 9, surgem figurações de árvores com a mesma estética de Eckelbo (especialmente os ramos terminados em gancho), mas de forma mais simples e sem o pássaro no topo (com exceção de Sö 327).
Fonte: Överhogdal (2002)

O centro é ocupado pelo desenho de uma árvore, tendo um pássaro no topo e outro na base. Ao lado esquerdo, um cavalo com oito patas sugere ser a representação de Sleipnir, o corcel de Odin.

Outras fontes visuais confirmam nosso referencial. Na runestone Gs 9, que também contém dois elementos nibelungianos (Sigurd matando Fáfnir e um homem portando o anel Andvaranaut), a árvore do monumento prolonga-se acima de uma cruz, formando vários galhos e um tronco central (como em Gs 2). No bloco de Ledbeg (Ög 181), a base da gravura de uma cruz possui várias raízes. Em U 1163 uma cruz é toda envolvida pelos ramos de uma árvore, enquanto que em $U$ 1175 repete-se o mesmo motivo, além de um anel centralizar a figura do símbolo cristão. 
No bloco de Gårdby, ao contrário, uma ramificação arbórea aparece na base de uma cruz. Com isso, verificamos que a conversão à nova religião não destituiu os simbolismos anteriores, sendo a árvore/cruz identificada ao centro, ao eixo do mundo - reguladora do destino, da ordem cósmica e do homem.

\section{Cosmologia}

O nome Yggdrasill ("cavalo de Odin") é uma referência ao fato de Odin ter se autoimolado nesta árvore (Hávamál 138). Ela é o centro do universo e o divide em três regiões cósmicas distintas em um eixo vertical: o plano celestial dos deuses, o plano intermediário dos humanos e gigantes, o plano inferior dos mortos - o submundo (figura 4). Apesar deste quadro cósmico ser tradicionalmente inferido pelas fontes, a relação de Yggdrasill com os nove mundos não é muito clara, sendo difícil estabelecer as fronteiras entre eles (DAVIDSON, 2004, p. 161).
Figura 3- llustração de manuscrito da Edda de Snorri, 1680 (ÁM 738 4to).

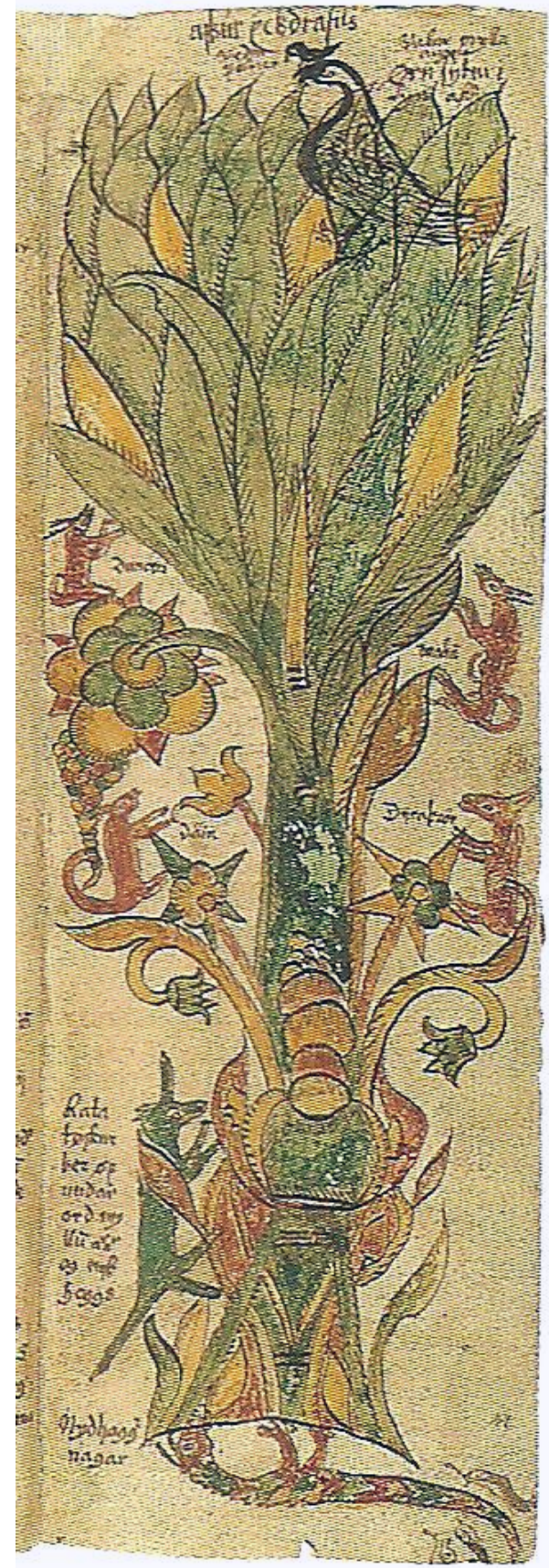

Fonte: Boyer (2004, p. 27).

Nesta colorida pintura setecentista, percebemos claramente a árvore do mundo (Yggdrasill), tendo ao topo a águia, no tronco os quatro cervos e o esquilo Ratatosk, enquanto que as raízes ficam localizadas o dragão Nidhogg e as serpentes dos mortos, todos descritos por Snorri Sturlusson em sua Edda. 
Muitas pinturas e ilustrações desde o Oitocentos colocam em uma única imagem a concepção cosmológica dos escandinavos (essencialmente dentro do quadro que nos referimos acima: um eixo vertical estruturado pela Yggdrasill e outro eixo, horizontal, definido pela Terra Média, oceano e Terra dos gigantes), mas alguns escandinavistas atualmente estão questionando esse modelo de interpretação. Para eles, tanto a ideia de uma axis vertical, quanto de três níveis e a posição celeste dos deuses foi influenciada pelo cristianismo, não tendo base pagã (WELLENDORF, 2004, p. 51-53), ou ainda, as referências astronômicas da poesia escáldica foram influenciadas pela tradição clássica (ROSS, 2012, p. 199-207). Não concordamos com esses pontos de vista, tendo como respaldo duas perspectivas: a de fontes visuais da Escandinávia da Era Viking e mitos de outras culturas.

Na pedra de Altuna (Suécia, século XI), em uma das faces gravadas, percebemos nitidamente três cenas agrupadas em sentido vertical. A primeira, situada no topo, com uma figura masculina com um pássaro no ombro e cortado por três linhas horizontais (sendo que na terceira ele apoia os pés) é interpretada como Odin (a esfera divina); o segundo nível, intermediário, contém a representação de um homem montado em um cavalo; no terceiro nível, temos a figura de Thor pescando a serpente do mundo - considerada o nível do submundo (SØRENSEN, 2002, p. 127). Na runestone de Sanda 1 (Suécia, Era Viking), logo acima de três figuras masculinas em movimento, no topo da monumento, foi gravado um nicho retangular, representado uma mulher e um homem sentados, além de um pássaro, possivelmente Odin e Frigg em seus tronos em Asgard. Em outras estelas gotlandesas, como Hammar I, Ardre VIII e Taengelgaerda, também podemos perceber claramente um conjunto de imagens em níveis, sendo que o inferior é ocupado por embarcações e cenas de morte, enquanto que as superiores contém representações do Valhalla e de Odin. 
Figura 4- Yggdrasill e os nove mundos, ilustração de Robert Guillemette

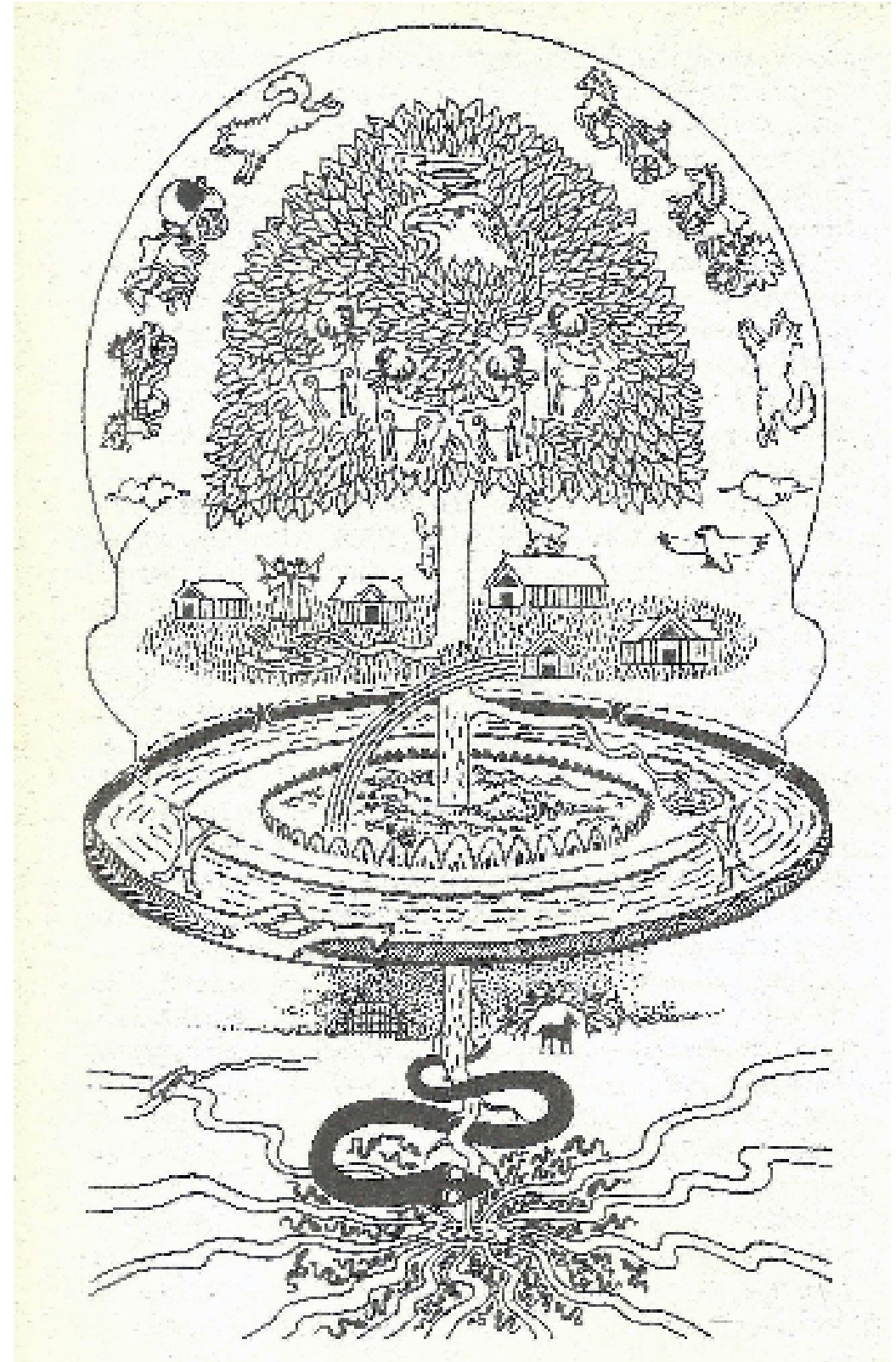

Fonte: Byock (2005, p. xxvi).

A imagem reconstitui os princípios básicos da cosmologia escandinava constantes nas duas Eddas. Um lobo corre atrás do carro da deusa Sol, enquanto outro persegue o deus Máni (Lua) (Vafprúðnismál 23). A parte superior, a copa da árvore, é ocupada por uma águia, logo acima de quatro cervos (Gylfaggining 16). O seu tronco forma o mundo dos deuses, Asgard, do qual emerge uma ponte (Bifrost), que se liga à Terra Média (Midgard), o mundo dos homens (Gylfaggining 41). Nos contornos, um muro separa Midgard de Jotunheim, a terra dos gigantes. Quatro anões demarcam os pontos cardeais, enquanto uma serpente abarca o mundo ao morder a própria cauda (Midgardsomr, arremessada ao oceano por Odin). Logo abaixo, as raízes são envolvidas por outra serpente, Nidhogg, que é acompanhada por dezenas de pequenas serpentes. No mesmo nível, o cão Garm guarda as portas de Hel (Grimnismál 25-44). Temos aqui representados os níveis básicos do cosmos nórdico, sendo três verticais (o mundo dos deuses, dos homens e o submundo) e três horizontais (o mundo dos humanos, dos gigantes e o oceano ocupado pela serpente). 
A existência de um pilar cósmico separando três zonas distintas, a celestial dos deuses, a intermediária dos homens e a inferior dos mortos, ocorre em diversos povos asiáticos, orientais, europeus, polinésios, africanos e americanos (ELIADE, 1998, p. 287-317). A base comum a todos eles seriam mitos xamânicos, mas sua difusão não seria necessariamente por contato cultural direto ou tendo uma origem fenomenológicoarquetípica, mas pela simples observação de fenômenos astronômicos. A ideia de morada celestial dos principais deuses de quase todas as culturas do mundo é resultado da constatação da imensidão da abóbada celeste, do qual o cristianismo apenas referendou: "O simbolismo da sua transcendência se deduz da simples tomada de consciência da sua altura infinita. $O$ ser 'altíssimo' é algo que se torna necessariamente um atributo de divindade" (ELIADE, 2010, p. 40). E o simbolismo do centro (manifestado em montanhas, pilares e árvores cósmicas) seria basicamente advindo da observação da estrela polar (alfa da constelação da Ursa Menor) - que no hemisfério norte é quase fixa, pela sua proximidade com o polo celeste boreal - sendo que as constelações parecem se movimentar em seu entorno. Elas criam figurações de prego, estaca, pilar, buraco no céu, centro do mundo, em grande parte das culturas euro-asiáticas (ELIADE, 1998, p. 289-295) e na Escandinávia da Era Viking (DAVIDSON, 2001, p. 69).

\section{Astronomia}

Vários pesquisadores de Etnoastronomia já sugeriram que para o referencial nórdico medieval, a árvore Ygdrassill seria a Via Láctea (STEPHANY, 2006, p. 5; OGIER, 2002; JÓNSSON, 2011). A Via Láctea apresenta-se no céu (em condições de boa visibilidade e céu escuro) como uma faixa pálida por toda a abóbada celeste (RIDPATH, 2011, p. 74), e não é difícil imaginar um tronco de árvore com diversos ramos. Apesar de não existirem fontes documentais da Era Viking que possam confirmar diretamente essa hipótese, nós também a utilizamos, baseados em material comparativo. Algumas áreas geográficoculturais estreitamente conectadas com a Escandinávia, como a região finlandesa, a báltica e a estoniana, preservaram diversos cantos populares e tradições folclóricas com essa associação (ELIADE, 1998, p. 300; KUPERJANOV, 2002, p. 55-56).

Partindo da hipótese de que a Yggdrasill seja uma figuração da Via Láctea, então a árvore gravada no bloco de Ockelbo pode ser também uma representação da extremidade de nossa galáxia. A pedra rúnica em questão ainda apresenta um importante detalhe - a serpente que envolve o conjunto apresenta sua cauda e cabeça projetando-se abaixo da árvore. Aqui reiteramos nossas pesquisas anteriores, que demonstram a tendência nórdica em associar o simbolismo da serpente-dragão de forma dinâmica (LANGER, 2007, p. 106-141), isto é, as narrativas míticas podem ser percebidas de forma analógica no pensamento medieval ("o semelhante evoca o semelhante)" (FRANCO JÚNIOR, 2010, p. 107). A similitude entre bestas no imaginário mítico foi algo muito utilizado na iconografia da Escandinávia medieval, mesmo após a cristianização (como a serpente de Thor assimilada ao Leviatã bíblico: a mesma imagem pagã passou a ter outro sentido, definido pela analogia). (LANGER, 2007, p. 106-141).

Em Ockelbo, o detalhe superior do corpo da serpente sendo perfurado pela espada, remete à narrativa de Sigurd matando o dragão Fáfnir. O fato da serpente do bloco contornar 
todo o conjunto de gravuras associa, por sua vez, ao detalhe de Jormungand entrelaçar toda a Terra Média. E o fato da sua cabeça e rabo estar abaixo da árvore, vincula-se com a narrativa de Nidhogg, o dragão que se localizava logo abaixo das raízes de Hel em Yggdrassill, devorando os mortos (Grimnísmál 32). Em outros conjuntos visuais, como em Sanda IV (Gotland, Súecia pré-Viking), o centro do monumento é ocupado pelo desenho esquemático de uma árvore com nove ramos, cujas raízes são fixadas em uma linha horizontal, separando a mesma da figura de uma besta, semelhante aos dragões-serpentes de outros conjuntos. Um barco abaixo deste animal pode reforçar o simbolismo da morte ou do reino dos mortos que tradicionalmente se localizava abaixo de Yggdrasill (o submundo).

Figura 5- Detalhe da inscrição rúnica de Ramsundsberget (Sö 101).

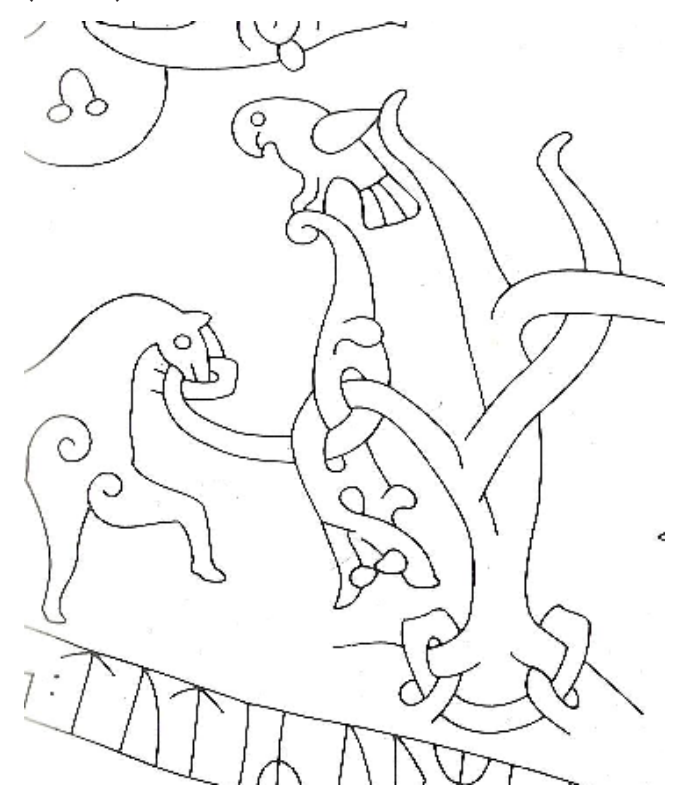

Fonte: Fell (2001, p. 185).

O cavalo Grani está amarrado em uma árvore, cujo topo se situa uma ave de rapina. O mesmo tronco da ave transforma-se em uma serpente-dragão, mais abaixo. topo é habitado por um pássaro e em sua base/raiz por uma serpente-dragão é fundamental em nossa interpretação. Ela é comum a diversos povos espalhados pelo mundo, da Eurásia à América précolombiana, e como nas fontes nórdicas, ambos os animais que a habitam são inimigos, sendo a serpente assimilada à terra e a ave ao céu (BOYER, 1981, p. 210). Como no caso escandinavo, a forma mais usual do pássaro inimigo da serpente nos diversos mitos euro-asiáticos é a de uma águia (ELIADE, 1998, p. 302). Na inscrição rúnica de Ramsundsberget (Sö 101), temos um detalhe que alude a essa representação: no topo de uma árvore, repousa uma ave cujo bico é retorcido para baixo e com ponta - de forma muito semelhante aos pássaros de rapina enquanto que um galho voltado para baixo transforma-se na cabeça de um dragão (figura 5). Em um bloco que segue esse padrão icônico (Sö 327, mas realizado depois da cristianização), a mesma árvore, só que sem o detalhe do pássaro, transforma-se em uma serpente com a língua de fora. Uma das mais surpreendentes similitudes visuais com a área nórdica surge com os Maias. Na estela 25 de Izapa (figura 6), no topo da árvore cósmica (interpretada como a Via Láctea), pousa o pássaro divino Vucub Caquix (visto como a constelação de Ursa Maior), enquanto que na base, o tronco transforma-se em um crocodilo (percebido como a constelação de Escorpião) (AVENI, 2011, p. 37). Em outra imagem dos Maias, mas desta vez a pintura de um codex, também foi representada a árvore cósmica, ocupada pelo pássaro, mas na base foi representado um escorpião - neste caso, os Maias interpretaram o agrupamento estelar da mesma forma que no mundo oriental e clássico (AVENI, 2011, p. 37).

A imagem de uma árvore cósmica cujo 
Figura 6- Estela 25 de Izapa.

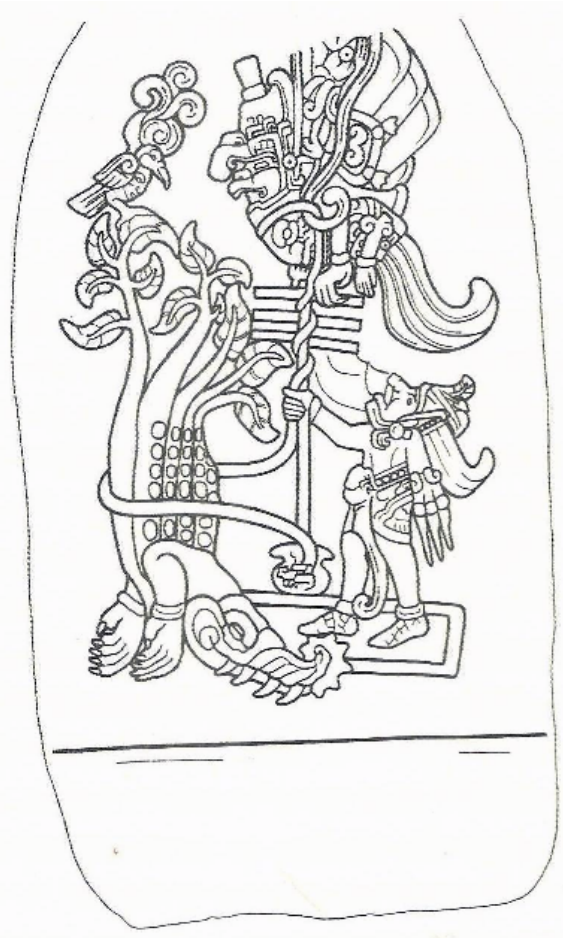

Fonte: Aveni (2011, p. 36).

Trata-se de uma cena do Popol Vuh 4, livro sagrado dos Maias, onde um dos heróis gêmeos enfrenta o pássaro divino Vucub Caquix (apoiado na árvore, assimilada com a Via Láctea). Na cena inferior, a árvore transforma-se em um crocodilo (identificado à constelação de Escorpião).

Do mesmo modo, alguns escandinavistas acreditam que a Ygdrasill seja a Via Láctea, enquanto que a constelação de Cisne possa ser a águia e o dragão Nidhogg a constelação de escorpião (STEPHANY, 2006; OGIER, 2002). Compartilhamos deste referencial, mas com alguns adendos. Utilizando o programa de planetário Stellarium (CHEREÁU, 2012) reconstituímos o céu da Escandinávia para o ano mil d. C. (final da Era Viking), tomando como localidade a cidade de Estocolmo $\left(59^{\circ}\right.$ de latitude norte, figura 7$)$. Durante todo este ano, tanto a Via Láctea quanto
Cisne são visíveis, e especialmente nos meses de maio a julho esta constelação está situada no zênite (ponto mais vertical e elevado sobre o observador), o que parece confirmar a posição do pássaro no topo da árvore cósmica no bloco de Eckelbo. Cisne (Cygni, Cyg) é uma das mais destacadas constelações do céu setentrional, facilmente identificada em forma de uma grande cruz, cuja principal estrela (Deneb), localiza-se na cauda (RIDPATH, 2011, p. 164). Vários folclores astronômicos, como os das regiões do Leste europeu e Báltico, associam essa constelação com um pássaro migratório (KUPERJANOV, 2002, p. 53). Quanto à constelação de Escorpião (Scorpii, Sco), constitui uma das mais belas, brilhantes e facilmente reconhecíveis agrupamento de estrelas do firmamento (TIRION; RIDPATH, 1986, p. 220). Um importante detalhe de nossa reconstituição astronômica do céu nórdico favorece sua identificação com a serpente Nidhogg. Escorpião emerge no horizonte sul entre os meses de janeiro a julho, primeiramente de madrugada, passando depois para horários crepusculares, mas sempre sendo visível por poucas horas e minimamente elevado cima do horizonte. Isso corresponde à ideia de um animal situado no submundo, ctônico e associado aos mortos. Assim, temos uma constelação situada em posição muito elevada no céu (Cisne), enquanto outra está sempre visível na linha do horizonte (Escorpião), o que parece confirmar o mito presente no mundo nórdico e em várias partes do mundo, da oposição entre a águia celeste e a serpente do submundo (figura 7).

Outros detalhes do bloco de Ockelbo merecem atenção. O homem segurando um anel e com a outra mão um ramo inferior da árvore, ao lado da cabeça da serpente, é comumente interpretado como 
o anão Andvari ou o próprio Sigurd. Em nossa reconstituição do céu escandinavo, pela posição em relação à constelação de Cisne e do Escorpião, podemos considerar a constelação de Coroa Boreal como tendo sido interpretada como o anel de Andvari (Andvaranaut), visto que ela é brilhante, formando uma espécie de argola com sete estrelas.

Figura 7- Reconstituição do céu sueco no ano mil d.C. (Estocolmo, 04 de maio de 1000, 20h, FOV 150 15.8 FPS, Latitude N $59^{\circ} 19^{\prime}$ Longitude E $18^{\circ} 4^{\prime}$.

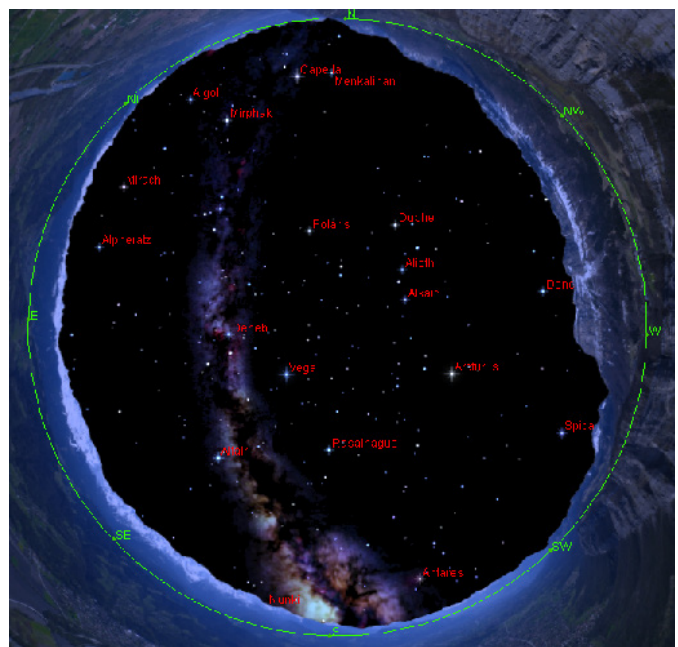

Drävle temos sua associação com os mitos nibelungianos e Yggdrasill. A proximidade da constelação da Coroa Boreal com a Via Láctea e sua forma circular, com certeza, deve ter chamado muito a atenção dos escandinavos.

Outra constelação que impressiona é a de Águia, abaixo de Cisne e também situada acima da Via Láctea. Ela pode ser tanto a representação de outro pássaro, semelhante à águia, quanto a representação de um galo (presente em Ockelbo e em outros conjuntos

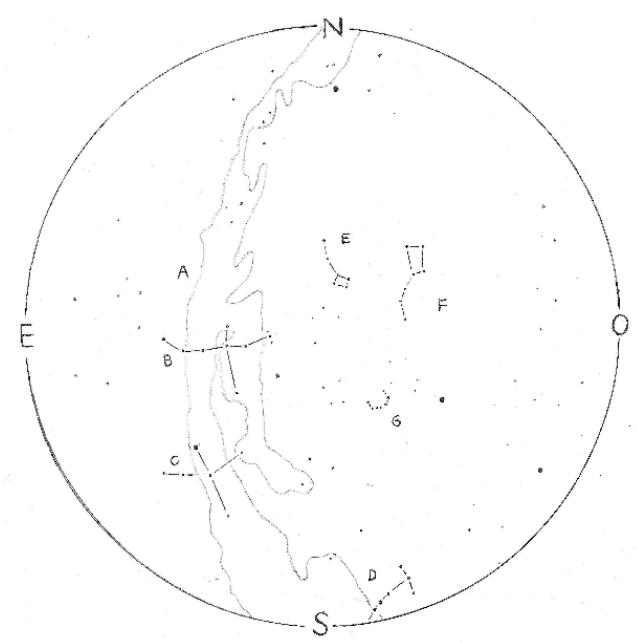

Fonte: Programa Redshift 7 Launcher.

Imagem da direita: Ilustração de Johnni Langer baseado no programa Redshift 7 Launcher: os nomes em itálico correspondem ao padrão Ocidental de configuração e os nomes entre parênteses suas possíveis correspondentes nórdicas: A - Via Láctea (Yggdrasill); B - Cisne (Águia); C - Águia (Galo/pássaro); D - Escorpião (Nidhogg); E - Ursa Menor (Carro de Friga); F - Ursa Maior (Carro de Odin); G - Coroa Boreal (Anel de Andvari). A estrela Polaris situa-se na extremidade do cabo da Ursa Menor. A estrela Deneb localiza-se na cauda de Cisne e Altair na de Águia. Por sua vez, Antares está pouco abaixo da cabeça de Escorpião. Outras importantes estrelas visíveis nesta reconstituição são Arcturus (constelação de Boieiro), situada à direita da Coroa Boreal, Spica (constelação da Virgem), na direção sudoeste e Capela (constelação do Cocheiro), no extremo norte.

Alguns pesquisadores interpretaram a mesma como sendo o dedo do gigante Aurvándil (PERSSON, 2003), um mito estelar presente no Skáldskaparmál 17, mas acreditamos que este se trata do nome de uma estrela, ao qual ainda é motivo de debate para sua identificação, e não de uma constelação. O símbolo do anel é presente em várias estelas e monumentos da Era Viking, como Taengerlgaerda, Ardre III, Martebo I, e mais especificamente em Gs 9, Gs 2 e nibelungianos, como Gs 2). O galo é mencionado nos poemas éddicos como sendo um animal presente tanto em Asgard (Gullimkambi) quanto em Hel, anunciando presságios (Völuspá 43). De todo modo, algumas representações visuais da Era Viking retratam dois pássaros na Ygdrasill (como em Sö 101), assim como o folclore astronômico euro-asiático, sugerindo que os dois agrupamentos estelares da Via Láctea (Cisne e Águia), retomaram simbolismos 
específicos da duplicidade das aves na mitologia escandinava: dois corvos de Odin; uma águia com um pássaro em sua fronte; dois galos; dois pássaros que conversam com Sigurd em um bosque.

O último detalhe de Ockelbo que nos interessa de um ponto de vista etnoastronômico é a carroça situada acima da árvore. Pode ser que seja uma simples gravura do cotidiano, mas a representação deste tema é muito rara nas fontes visuais escandinavas. Correlacionada às outras imagens em volta da árvore, talvez seja uma referência à carroça de Odin - identificada com a constelação de Ursa Maior (Ursa Majoris, UMa). A parte mais famosa desta destacada constelação são sete estrelas que formam uma espécie de concha com cabo, interpretada de diversas maneiras pelas mais variadas culturas (panela pelos escravos dos Estados Unidos, urso pelos indígenas norte-americanos, entre outros). (VERDET, 1987, p. 31-33).

Alguns povos germânicos da Europa Alto medieval interpretaram esse agrupamento como sendo o carro de Carlos Magno ou do rei Artur, enquanto que os eslavos e anglo-saxões a denominaram de carroça do camponês (KUPERJANOV, 2010, p. 55). O fato de Ursa Maior ser o desenho estelar mais famoso dos céus se deve a sua utilização como guia para a estrela Polaris (ou Cynosura) - essencialmente para orientação, devido a sua proximidade com o Polo Norte Celeste (TIRION; RIDPATH, 1986 , p. 242, 246) e como demarcador de tempo e calendário (KUPERJANOV, 2010, p. 51). Os vikings foram muito conhecidos por sua perícia náutica pelo alto mar, além de explorações em diversos pontos da Europa, incluindo o Mediterrâneo. Como outros povos exploradores do hemisfério norte, a exemplo dos polinésios, eles podem ter utilizado a estrela Polaris para orientação astronômica, enfatizando as constelações da Ursa Maior e Menor em narrativas míticas que infelizmente foram perdidas. No final da Idade Média, algumas regiões germânicas preservaram a tradição de identificar esse agrupamento como as sete estrelas do carro de Wotan (Odin) (WARD, 2012) e entre os suecos como Odin vagn (carroça de Odin), que possivelmente foi contraído pelos finlandeses para Otava (KUPERJANOV, 2010, p. 55). O poema éddico Sigrdrifumál 15 utiliza a expressão Reið Rôgnis, carro de Rognis (Odin), o que parece indicar a mesma tradição, só que mais antiga. $\mathrm{Na}$ área Maia, o deus Sete Araras (Vucub Caquix) é identificado com a Ursa Maior, e do mesmo modo que na gravura de Eckelbo, aparece relacionado com a árvore do mundo (AVENI, 2011, p. 37), a exemplo da estela 25 de Izapa (figura 6).

\section{Conclusão: o sentido das imagens nórdicas}

O bloco de Ockelbo, enquanto fonte visual produzida na Era Viking, possui muitas semelhanças de sentido com outros monumentos da mesma época e região, a saber - denotam principalmente um sentido de força, destreza, coragem e virtudes exigidas pela sociedade escandinava, constituindo-se basicamente em modelos de comportamento social. A mescla de cenas sem sequência ou a justaposição de diferentes narrativas míticas e símbolos nestes monumentos, tem sido geralmente interpretado como um padrão normal na confecção destas imagens (FUGLESANG, 2006, p. 9). A seleção de algumas cenas específicas da tradição mitológica oral permite perceber que as imagens acabam funcionando conectadas às exigências e finalidades da sociedade na qual a linguagem visual tem curso (GOMBRICH, 
2007, p. 78).

Também acreditamos em outras possibilidades interpretativas. Como relatamos no início deste texto, a inclusão de cenas cotidianas, mesclada ao ciclo nibelungiano (com possíveis sentidos cosmológicos e astronômicos em nossa perspectiva), são vistas em um primeiro instante, como cenas desconexas (STERN, 2009, p. 900). Mas para o escandinavo, beber e estar jogando em sua casa, durante o inverno, não era visto como algo necessariamente separado dos deuses e heróis míticos. Assim, o mundo dos homens fazia parte de um cosmos estruturado pelos deuses, onde o espaço laico não era isolado do espaço sagrado. Esse universo era mutável e dinâmico, incorporando o macro e micro conjuntamente - sendo a analogia a base do pensamento nórdico: "Entre o homem e o mundo não havia diferença estrutural" (FRANCO JÚNIOR, 2010, p. 99).

Apesar das fontes escandinavas medievais terem preservado alguns mitos estelares, o folclore e as tradições astronômicas da Era Viking ainda necessitam de muitas pesquisas. A relação entre fontes visuais e literárias ainda demanda muitas questões e problemáticas. Resta aos pesquisadores futuros a utilização de pesquisas interdisciplinares, unindo as áreas da História, Mitologia, Folclore e Astronomia. Certamente nosso entendimento da percepção do nórdico sobre o cosmos será ampliado: “Nessa relação que funde modelo e imagem, e que constantemente inverte e subverte toda tentativa doutrinária de causalidade, apenas o pensamento analógico possibilitava o pleno mergulho, ao mesmo tempo emocional e racional nas profundezas do mistério cosmológico" (FRANCO JÚNIOR, 2010, p. 128).

\section{Fontes Primárias}

Grímnismál, Hávamál, Sigrdrífumál, Vafprúðnismál, Völuspá. In: The Poetic Edda. Tradução de Lee Hollander. Austin: University of Texas Press, 2008.

Gylfagining, Skáldskaparmál.In:STURLUSON, Snorri. The Prose Edda. Tradução de Jesse Byock. London: Penguin Books, 2005.

Popol Vuh. Tradução de Raul Xavier. Rio de Janeiro: Cátedra, 1979.

\section{Referências}

AVENI, Anthony. O mistério Maia: história, ciência e o fim dos tempos. São Paulo: Novo Século, 2011.

BAITY, Elisabeth Chesley. Archaeoastronomy and Ethnoastronomy so far. Current Antropology, v. 14, n. 4, p. 389-449, 1973.

BOYER, Régis. Les dieux, les hommes, le destin. In: GLOT, Claudine; LE BRIS, Michel (Dir.). L'Europe des Vikings. Paris: Hoebeke, 2004.

BOYER, Régis. Yggdrasill: la religion des anciens scandinaves. Paris: Payot, 1981.

BYOCK, Jesse. The world tree, Yggdrasill. In: . The Poetic Edda. London: Penguin

Books, 2005. p. xxvi-xxx.

CHEREÁU, Fabien et al. Stellarium 0.11.3, 2012. Disponível em: <www.stellarium. org > . Acesso em: 14 abr. 2013.

DAVIDSON, Hilda. Deuses e mitos do norte 
da Europa. São Paulo: Madras, 2004.

DAVIDSON, Hilda. The lost beliefs of Northern Europe. New York: Routledge, 2001.

DÜWELL, Klaus. On the Sigurd representations in Great Britain and Scandinavia. In: JAZAVERY, Mohanmad (Ed.). Languages and cultures: studies in honor of Edgar C. Polomé. New York, 1988. p. 133-156.

ELIADE, Mircea. Tratado de história das religiões. São Paulo: Martins Fontes, 2010.

ELIADE, Mircea. O xamanismo e as técnicas arcaicas do êxtase. São Paulo: Martins Fontes, 1998.

FELL, Christine. From Odin to Christ. In: GRAHAM-CAMPBELL, James (Org). The Viking World. London: Frances Lincoln, 2001. p. 172-193.

FRANCO JÚNIOR, Hilário. Os três dedos de Adão: ensaios de mitologia medieval. Modelo e imagem. São Paulo: Edusp, 2010.

FUGLESANG, Signe Horn. Iconographic traditions and models in Scandinavian imagery. In: INTERNATIONAL SAGA CONFERENCE, 13., 2006, Durham.

GOMBRICH, Ernest. Arte e ilusão: um estudo da psicologia da representação pictórica. São Paulo: Martins Fontes, 2007.

JÓNSSON, Bjorn. The ash of Yggrdasill/Milk Way, 2011. Disponível em: < http://www. germanicmythology.com/ASTRONOMY/ images/BjornJonssonVikingStarmap.jpg > . Acesso em: 18 abr. 2013.
Folklore: Electronic Journal, Estonian, v. 44, p. 51-60, 2010.

KUPERJANOV, Andres. Pseudomythological constelattion maps. Folklore: Electronic Journal, Estonian, v. 32, p. 37-62. 2006.

KUPERJANOV, Andres. Names in Estonian folk astronomy: from Bird's way to milk way. Folklore: Electronic Journal, Estonian, v. 22, p. 49-61, 2002.

LANGER, Johnni. O mito do dragão na Escandinávia (Parte três: as sagas e o sistema nibelungiano). Brathair, São Luis, v. 7, n. 2, p. 106-141, 2007.

LANGER, Johnni. As estelas de Gotland e as fontes iconográficas da mitologia Viking. Brathair, São Luis, v. 6, n. 1, p. 10-41, 2006.

MAREZ, Alain. Anthologie runique. Paris: Les Belles Lettres, 2007.

OGIER, James. Eddic Constellations. Western Michigan University, 2002. Disponível em: < http://www.roanoke.edu/forlang/ogier/ EddicConstellations.htm > . Acesso em: 8 set. 2012.

ÖVERHOGDAL. Överhogdal. 2002. Disponível em: <http://www.overhogdal.se/english. htm > . Acesso em: 15 maio 2013.

PERSSON, Jonas. Norse Constellations, 2003. Disponível em: <http://www. digitaliseducation.com/resources-norse. html > . Acesso em: 15 maio 2013.

RIDPATH, Ian. Astronomia. São Paulo: Zahar, 2011.

ROSS, Margaret Clunies; GADE, Kari. 
Cosmology and the skaldic poetry. Journal of English and Germanic philology, v. 11, n. 2, p. 199-207, 2012.

SAWYER, Birgit. The Viking-age rune-stones: custom and commemoration in early medieval Scandinavia. Oxford: Oxford University Press, 2003.

SØRENSEN, Preben Meulengracht. Porr's fishing expedition. In: ACKER, Paul; LARRINGTON, Carolyne (Ed.). The Poetic Edda: essays on Old Norse mythology. New York: Routledge, 2002. p. 119-138.

STEPHANY, Timothy J. Yggdrasill and Ymir's skull: the cosmology of Nordic myth, 2007. Disponível em: < http://timothystephany. com/papers/Article12-Cosmology.pdf > . Acesso em: 15 out. 2012.

STEPHANY, Timothy J. Ancient Skies of the Northern Europe: stars, constelattions, and the Moon in Nordic mythology, 2006. Disponível em: < http://timothystephany.com/ papers/ Article01-NightSky.pdf > . Acesso em: 15 out. 2012.

STERN, Marjolein. Sigurð Fáfnisbani as commemorative motif. In: NEY, Agneta et al. (Ed.). Á autrvega: saga and East Scandinavia. Gävle: Gävle University Press, 2009. p. 898905.

VERDET, Jean-Pierre. O céu: mistério, magia e mito. São Paulo: Objetiva, 1987.

TIRION, Wil; RIDPATH, Ian. Guía de las estrellas y los planetas de los hemisférios norte y sul. Barcelona: Ediciones Omega, 1986.

WARD, Cristie. Viking Age Star and Constellation Names. 2012. Disponível em:
< http://www.vikinganswerlady.com/stars. shtml > . Acesso em: 10 out. 2012.

WELLENDORF, Jonas. Homogeneity and heterogeneity in Old Norse cosmology. In: ANDRÉN, Anders et al. (Ed.). Old Norse religion in long-term perspectives. Lund: Nordic Academic Press, 2004. p. 50-53. 
